\title{
Retrospective analysis to describe associations between tumor necrosis factor alpha inhibitors and COPD-related hospitalizations
}

This article was published in the following Dove Press journal:

International Journal of COPD

19 July 2017

Number of times this article has been viewed

\section{Neil A Accortt' \\ James B Chung ${ }^{2}$ \\ Machaon Bonafede ${ }^{3}$ \\ Brendan L Limone ${ }^{3}$ \\ David M Mannino ${ }^{4}$}

'Amgen, Inc., Center for Observational Research, Thousand Oaks, CA, ${ }^{2}$ Amgen, Inc., US Medical Organization, Thousand Oaks, CA, ${ }^{3}$ Truven Health Analytics, an IBM Company, Outcomes Research, Cambridge, MA, ${ }^{4}$ University of Kentucky College of Public Health, Lexington, KY, USA
Correspondence: Neil A Accortt Amgen, Inc., One Amgen Center Drive, MS24-2-A, Thousand Oaks, CA 91320, USA

Tel +l 8054477196

Email naccortt@amgen.com
Background: Limited information exists on the impact of tumor necrosis factor inhibition on COPD exacerbations. This retrospective study characterized this impact among COPD patients with underlying autoimmune conditions, exposed to tumor necrosis factor inhibitors (TNFi) and/or non-biologic disease-modifying antirheumatic drugs (DMARDs).

Patients and methods: Adult COPD patients with $\geq 1$ diagnosis for rheumatoid arthritis (RA), psoriasis (PsO), psoriatic arthritis (PsA), or ankylosing spondylitis (AS) before or within 6 months following the index COPD diagnosis were identified from the Truven Health MarketScan ${ }^{\circledR}$ databases. Patients were required to have a second claim for RA, PsO, PsA, AS, or DMARD use (biologic or non-biologic) prior to or up to 6 months following the index date. Incidence of COPD-related hospitalizations and emergency room (ER) visits was evaluated in relation to treatment with TNFi and/or DMARDs and other potential risk factors.

Results: The study cohort included 40,687 patients (untreated, 37.7\%; non-biologic DMARD, $35.4 \%$; TNFi + non-biologic DMARD, 18\%; TNFi, 8.8\%). The proportion of patients with a COPD-related hospitalization and the incidence of COPD-related hospitalization (per 100 person-years) were lowest in the TNFi cohort $(8.6 \% ; 3.54,95 \%$ confidence interval [CI]: 3.16-3.95) and the TNFi + non-biologic DMARD cohort (8.4\%; 2.85, 95\% CI: 2.63-3.08). In multivariate models, treatment with TNFi + non-biologic DMARD reduced the risk of COPD-related hospitalization or ER visits by $32 \%$ relative to non-biologic DMARDs (hazard ratio: 0.68 ; $95 \% \mathrm{CI}$ : $0.61-0.75)$.

Conclusion: In real-world settings, TNFi monotherapy confers similar risk for COPD-related hospitalization or ER visits as a non-biologic DMARD. Decreased risk was found among those treated with both TNFi and a non-biologic DMARD.

Keywords: COPD, TNF inhibitor, exacerbation, incidence, biologic DMARD

\section{Introduction}

COPD, characterized by airflow limitation, affects $>13$ million adults in the US. ${ }^{1}$ Current treatments, including inhaled corticosteroids, bronchodilators, and anticholinergics primarily provide symptomatic relief and appear to have little impact on natural disease history. ${ }^{2,3}$ In healthy individuals, inhalation of tumor necrosis factor alpha (TNF- $\alpha$ ) has been shown to increase airway hyper-responsiveness, one of the key symptoms in COPD. ${ }^{4,5}$ Further research has shown an excess of proinflammatory cytokines, specifically TNF- $\alpha$, in the sputum of patients with COPD. ${ }^{6-9}$ Thus, it is theorized that this cytokine, TNF- $\alpha$, may play a major role in maintaining the inflammatory state from which COPD patients suffer, and treatment with tumor necrosis factor inhibitors (TNFi) may help reduce airway inflammation. ${ }^{10}$ 
Studies have sought to examine the efficacy of TNFi in patients with COPD, both directly and indirectly, with mixed results. ${ }^{10-13}$ A randomized clinical trial with etanercept failed to demonstrate efficacy in COPD relative to oral prednisone; however, the study was limited by the short treatment duration (two doses) and timing of the treatment (ie, during an acute exacerbation). ${ }^{14}$ The most compelling evidence for efficacy of TNFi in COPD stems from a large observational study of 15,771 patients with rheumatoid arthritis (RA) and COPD being treated with etanercept or infliximab. ${ }^{13}$ Treatment with etanercept was associated with a significant reduction in the risk of COPD-related hospitalization (relative risk [RR]: 0.49, 95\% confidence interval [CI]: 0.29-0.82), whereas infliximab did not exhibit any significant impact. Along with TNF- $\alpha$, lymphotoxin alpha $(\mathrm{LT} \alpha)$ is a cytokine produced by lymphocytes which mediates a variety of inflammatory processes. The exact role of LT $\alpha$, which etanercept uniquely inhibits among the available TNF blocking agents in COPD is unknown, but its expression is upregulated in the sputum and lung tissue of COPD patients. ${ }^{15}$

Results of these studies suggest the potential for benefit of treatment with TNFi among patients with COPD, however, small sample sizes, short study periods, and analysis of few TNFi in these studies limit any conclusive findings. Thus, we sought to take advantage of TNFi use in the treatment of autoimmune disorders (RA, psoriasis [PsO], psoriatic arthritis [PsA], and ankylosing spondylitis [AS]) since 2006 where the majority of evaluated products were approved during the study period. Using administrative claims data, this study identified patients with one of the above disorders along with a diagnosis of COPD in order to characterize the risk of COPD hospitalizations and emergency room (ER) visits among patients who were exposed to TNFi and/or non-biologic disease-modifying antirheumatic drugs (DMARDs).

\section{Patients and methods \\ Data source}

This retrospective study employed the 2006-2013 Truven Health Analytics MarketScan ${ }^{\circledR}$ Commercial Claims and Encounters (Commercial) and Medicare Supplemental (Medicare) databases, which profile the health care experience (inpatient and outpatient) of individuals with employersponsored primary or Medicare supplemental health insurance. These databases contain only deidentified data and therefore Institutional Review Board approval to conduct this study was not necessary.

\section{Patient selection}

Adults $\geq 18$ years old with a primary or secondary diagnosis for COPD (International Classification of Diseases, Ninth Revision, Clinical Modification [ICD-9-CM] 490.xx-492. $\mathrm{xx}, 496 . x \mathrm{x}$ ) on a non-diagnostic claim (a service that was not performed to test for or 'rule out' a diagnosis) between January 1, 2006 and June 30, 2012 were identified (date of first COPD diagnosis = index date). Additionally, patients were required to have an inpatient or outpatient claim with a non-diagnostic diagnosis for RA (ICD-9-CM: 714.0x), PsO (ICD-9-CM: 696.1x), PsA (ICD-9-CM: 696.0x), or AS (ICD9-CM: 720.0x), and a second claim for RA, PsO, PsA, or AS, or use of a biologic or non-biologic DMARDs prior to or up to 6 months following the index date. Treatment of Crohn's disease (ICD-9-CM: 555.xx) or ulcerative colitis (ICD-9-CM: 556.xx) can include very different dosing schedules that may impact study outcomes, thus, patients with a diagnosis of either in the pre- and post-period were excluded.

Patients were further stratified into four treatment cohorts based on the use of TNFi or non-biologic DMARDs during the variable-length follow-up period: 1) TNFi only (adalimumab, certolizumab, etanercept, infliximab, golimumab) cohort; 2) TNFi + non-biologic DMARD (methotrexate, minocycline, sulfasalazine, hydroxychloroquine, leflunomide, cyclosporine, azathioprine, and gold sodium thiomalate) cohort; 3) Non-biologic DMARD only cohort; and 4) Untreated cohort. Treatment cohorts were mutually exclusive, patient data was only included in one treatment cohort based upon evidence of TNFi and/or non-biologic DMARD use during the post-index period.

\section{Study outcomes}

The proportion of patients having a COPD-related hospitalization was reported, and the incidence of COPD-related hospitalization per 100 person-years was assessed for each of the four treatment cohorts. Patients were followed with a fixed length of 12-month pre-index period and a variable length post-index period with a minimum of 12 months. Persontime at risk was defined as the time since index date to one of the following events, whichever occurred first: 1) COPD hospitalization, 2) inpatient death, 3) the end of enrollment, or 4 ) the end of data availability (June 30, 2013). In addition, a sensitivity analysis to test the robustness of the results was conducted to evaluate incidence of COPD-related ER visits or first COPD-related hospitalization. Patients with an ER visit prior to a COPD hospitalization were followed until the date of hospitalization for the primary study outcome. COPD-related hospitalizations were identified by primary 
or secondary diagnosis of COPD on any inpatient claims during the post-period. If the index COPD diagnosis was on an inpatient claim, the start of the study outcome evaluation period was shifted to the day following the discharge date of the index hospitalization. COPD-related ER visits were captured by primary or secondary diagnosis of COPD for ER services resulting in patients being discharged home.

\section{Other variables}

Patient demographic characteristics and clinical characteristics, including the Deyo-Charlson Comorbidity Index, comorbid medical conditions ( $\geq 1$ medical claim) and concomitant medications ( $\geq 1$ prescription claim) were measured at index date and during the 12-month pre-index period, respectively.

\section{Statistical methods}

Proportional hazards regression analyses were performed to identify factors contributing to the risk of COPDrelated hospitalization or ER use. The explanatory items included patient treatment cohort (TNFi only, TNFi + nonbiologic therapies, non-biologic DMARD only [reference]), baseline demographic characteristics, comorbidities and medication exposure. Analyses were conducted using SAS 9.3 (SAS Institute Inc., Cary, NC, USA).

\section{Results}

A total of 40,687 patients met study eligibility criteria and were included in the analysis. Of these, 15,347 (37.7\%) were not treated with either a TNFi or DMARD, 14,420 (35.4\%) were treated with a non-biologic DMARD only, 7,337 $(18.0 \%)$ were treated with both a TNFi and a non-biologic DMARD, and 3,583 (8.8\%) received treatment with a TNFi only (Figure 1) during the post-index follow-up period.

Overall, patients had an average age of 59.8 years (standard deviation [SD] 13.9 years). The majority were females $(67.3 \%)$, covered by a capitated health plan $(90.9 \%)$, and resided in the South region of the US (36.6\%) (Table 1); this distribution matches that of the underlying data source. There were some notable differences among the four treatment cohorts. In particular, the TNFi only cohort was younger, and had the highest proportion of males (41.8\%). Patients were followed for a mean of 830 days (SD 634 days), with the longest for the TNFi + non-biologic DMARD cohort

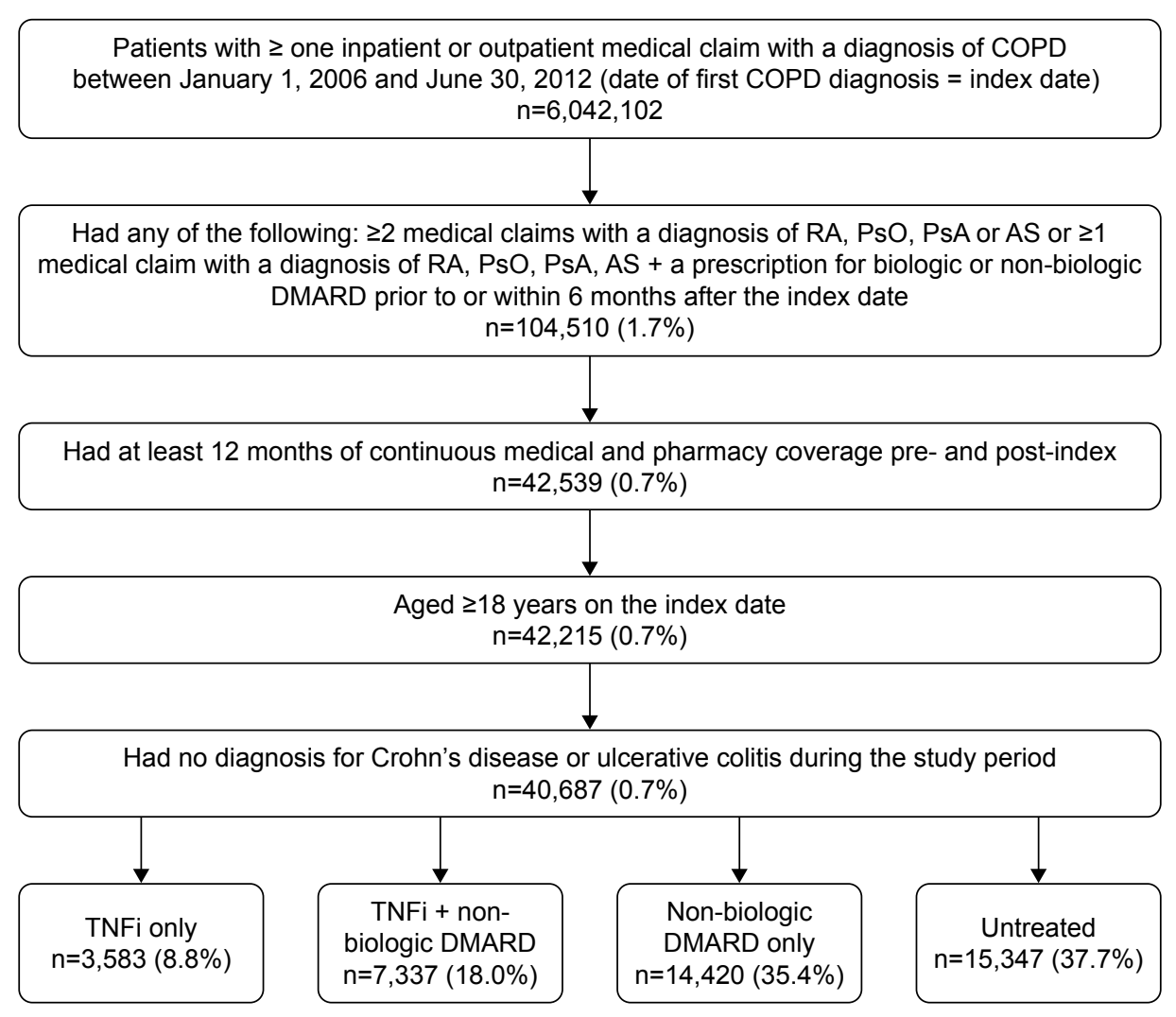

Figure I Patient selection.

Abbreviations: AS, ankylosing spondylitis; DMARD, disease-modifying antirheumatic drug; PsA, psoriatic arthritis; PsO, psoriasis; RA, rheumatoid arthritis; TNFi, tumor necrosis factor-alpha inhibitor. 
Table I Patient demographic characteristics

\begin{tabular}{|c|c|c|c|c|c|}
\hline \multirow{2}{*}{$\begin{array}{l}\text { Demographic } \\
\text { characteristics }\end{array}$} & \multirow{2}{*}{$\begin{array}{l}\text { All patients } \\
\mathrm{N}=40,687\end{array}$} & \multirow{2}{*}{$\frac{\text { TNFi only }}{n=3,583}$} & \multirow{2}{*}{$\begin{array}{l}\text { TNFi + DMARD } \\
\mathrm{n}=7,337\end{array}$} & \multirow{2}{*}{$\begin{array}{l}\text { DMARD only } \\
n=14,420\end{array}$} & \multirow{2}{*}{$\begin{array}{l}\text { Untreated } \\
n=15,347\end{array}$} \\
\hline & & & & & \\
\hline Age (years), mean (SD) & $59.8(13.9)$ & $55.0(13.5)$ & $57.3(12.0)$ & $61.9(13.1)$ & $60.2(15.0)$ \\
\hline \multicolumn{6}{|l|}{ Age group (years), n (\%) } \\
\hline $18-34$ & $\mathrm{I}, 720(4.2)$ & $258(7.2)$ & $280(3.8)$ & $380(2.6)$ & $802(5.2)$ \\
\hline $35-44$ & $3,531(8.7)$ & $497(13.9)$ & $739(10.1)$ & $914(6.3)$ & $1,381(9.0)$ \\
\hline $45-54$ & $8,240(20.3)$ & $947(26.4)$ & $1,769(24.1)$ & $2,548(17.7)$ & $2,976(19.4)$ \\
\hline $55-64$ & $13,329(32.8)$ & $\mathrm{I}, 094(30.5)$ & $2,702(36.8)$ & $4,829(33.5)$ & $4,704(30.7)$ \\
\hline$\geq 65$ & $13,867(34.1)$ & $787(22.0)$ & $\mathrm{I}, 847(25.2)$ & $5,749(39.9)$ & $5,484(35.7)$ \\
\hline Female, n (\%) & $27,373(67.3)$ & $2,087(58.3)$ & $5,370(73.2)$ & $10,283(7 \mid .3)$ & $9,633(62.8)$ \\
\hline \multicolumn{6}{|l|}{ Geographic region, n (\%) } \\
\hline Northeast & $6,280(I 5.4)$ & $538(15.0)$ & $950(13.0)$ & $2,080(14.4)$ & $2,712(17.7)$ \\
\hline North Central & $12,556(30.9)$ & I,002 (28.0) & $2,166(29.5)$ & $4,704(32.6)$ & $4,684(30.5)$ \\
\hline South & $|4,89|(36.6)$ & $1,419(39.6)$ & $2,919(39.8)$ & $5,202(36.1)$ & $5,351(34.9)$ \\
\hline West & $6,588(16.2)$ & $587(16.4)$ & $1,243(16.9)$ & $2,323(16.1)$ & $2,435(15.9)$ \\
\hline Unknown & $372(0.9)$ & $37(1.0)$ & $59(0.8)$ & III (0.8) & $165(I . I)$ \\
\hline \multicolumn{6}{|l|}{ Insurance plan type, n (\%) } \\
\hline Capitated & $36,967(90.9)$ & $3,259(91.0)$ & $6,649(90.6)$ & I3,084 (90.7) & |3,975 (91.1) \\
\hline Non-capitated & $3,720(9.1)$ & $324(9.0)$ & $688(9.4)$ & I,336 (9.3) & I,372 (8.9) \\
\hline Days of follow-up, mean (SD) & $882(6 \mid 4)$ & $888(591)$ & $1,073(648)$ & 905 (609) & $767(580)$ \\
\hline
\end{tabular}

Abbreviations: DMARD, disease-modifying antirheumatic drug; SD, standard deviation; TNFi, tumor necrosis factor inhibitors.

(1,073 days, SD 648 days) and the shortest for the untreated cohort (757 days, SD 580 days) (Table 1).

Patients in the TNFi only cohort had slightly lower Deyo-Charlson Comorbidity Index scores during the baseline period. The most prevalent comorbidities included hypertension (45.0\%), hyperlipidemia (28.1\%), and Type II diabetes $(17.6 \%)$ with the highest prevalence seen in the untreated cohort. Over one-half of the patients had RA during the baseline with the highest proportion seen in TNFi + nonbiologic DMARD (78.3\%) and non-biologic DMARD only (70.5\%) cohorts. Nearly one-in-four patients were diagnosed with $\mathrm{PsO}$, with the highest in the TNFi only (39.8\%) or the untreated cohort (39.7\%). During the 12-month pre-period, $44.3 \%, 35.5 \%$, and $23.8 \%$ of study patients were treated with oral, intravenous (IV), and inhaled corticosteroids, respectively, and $19.2 \%, 10.0 \%$, and $2.7 \%$ were on short-acting beta-agonist (SABA), long-acting beta-agonist (LABA), and long-acting anti-muscarinics, respectively. The use of these medications increased during the follow-up period. The TNFi + non-biologic DMARD and the DMARD only cohorts consistently had higher use of these concomitant medications than the TNFi only and the untreated cohorts; the same pattern was observed for pre-period antibiotics use (Table 2).

The proportion of patients who had a COPD-related hospitalization during the follow-up period was lower for the TNFi only (8.6\%) and the TNFi + non-biologic DMARD cohort $(8.4 \%)$ than that for the non-biologic DMARD only
(11.7\%, both $P<0.0001)$ and the untreated cohort $(14.2 \%$, both $P<0.0001)$. Figures 2 and 3 display the unadjusted and adjusted time to first COPD-related hospitalization. The untreated cohort had the shortest mean time from the index COPD diagnosis to the first COPD-related hospitalization (356 days, SD 451 days). Incidence rates of COPD-related hospitalization per 100 person-years were lowest in the TNFi + non-biologic DMARD (2.85; 95\% CI: 2.63-3.08) and the TNFi only cohorts (3.54; 95\% CI: 3.16-3.95). Similar patterns were observed in a sensitivity analysis expanding the study outcome to include either COPD-related ER visit or first COPD-related hospitalization.

Results from multivariable analysis revealed that use of TNFi treatment + non-biologic DMARD reduced the risk of COPD-related hospitalization or ER visits by $32 \%$, relative to the non-biologic DMARD only patients (hazard ratio [HR]: 0.678; 95\% CI: $0.61-0.754)$. The hazard of hospitalization or ER visit between the TNFi only cohort and the non-biologic DMARD only cohort was statistically similar (HR: 1.003; 95\% CI: 0.862-1.167). After adjusting for other covariates including biologic and non-biologic DMARD use, hazard of COPDrelated hospitalization or ER visit were significantly higher in older patients (aged 45-54, 55-64, and $\geq 65$ years) as compared with patients aged $18-44(P<0.05$ for all $)$. Females had a lower hazard of hospitalization or ER visit than males (HR: 0.828; 95\% CI: 0.767-0.894) (Figure 4). Biologic DMARD use (adalimumab, infliximab, and etanercept), concomitant medication use (self-administered corticosteroids, SABA, 
Table 2 Patient clinical characteristics

\begin{tabular}{|c|c|c|c|c|c|}
\hline \multirow[t]{2}{*}{ Clinical characteristics } & \multirow{2}{*}{$\begin{array}{l}\text { All patients } \\
\mathrm{N}=40,687\end{array}$} & \multirow{2}{*}{$\frac{\text { TNFi only }}{n=3,583}$} & \multirow{2}{*}{$\begin{array}{l}\text { TNFi + DMARD } \\
n=7,337\end{array}$} & \multirow{2}{*}{$\begin{array}{l}\text { DMARD only } \\
n=14,420\end{array}$} & \multirow{2}{*}{$\begin{array}{l}\text { Untreated } \\
n=15,347\end{array}$} \\
\hline & & & & & \\
\hline Deyo-Charlson Comorbidity Index, mean (SD) & $1.5(1.6)$ & I.I (I.4) & $\mathrm{I} .4(\mathrm{I} .2)$ & $1.7(1.5)$ & $1.5(1.8)$ \\
\hline \multicolumn{6}{|l|}{ Baseline comorbid conditions, n (\%) } \\
\hline Anxiety & $2,990(7.3)$ & $260(7.3)$ & $474(6.5)$ & $913(6.3)$ & $\mathrm{I}, 343(8.8)$ \\
\hline Asthma & $5,209(12.8)$ & $424(11.8)$ & $922(12.6)$ & $1,963(13.6)$ & $1,900(12.4)$ \\
\hline Congestive heart failure & $2,714(6.7)$ & $137(3.8)$ & $260(3.5)$ & $1,011(7.0)$ & $\mathrm{I}, 306(8.5)$ \\
\hline Depression & $4,220(10.4)$ & $342(9.5)$ & $755(10.3)$ & $\mathrm{I}, 422(9.9)$ & $\mathrm{I}, 70 \mathrm{I}(\mathrm{II} . \mathrm{I})$ \\
\hline Hyperlipidemia & II,423 (28.I) & $899(25.1)$ & $1,658(22.6)$ & $3,938(27.3)$ & $4,928(32.1)$ \\
\hline Hypertension & $18,3 \mid 4(45.0)$ & $1,397(39.0)$ & $2,873(39.2)$ & $6,678(46.3)$ & $7,366(48.0)$ \\
\hline Obesity & $2,138(5.3)$ & $194(5.4)$ & $320(4.4)$ & $67 \mid(4.7)$ & $953(6.2)$ \\
\hline Osteoarthritis & $5,992(14.7)$ & $44 \mid(12.3)$ & $1,101(15.0)$ & $2,240(15.5)$ & $2,210(14.4)$ \\
\hline Osteoporosis & $3,060(7.5)$ & $179(5.0)$ & $576(7.9)$ & $1,316(9.1)$ & $989(6.4)$ \\
\hline Pneumonia & $1,606(3.9)$ & $98(2.7)$ & $216(2.9)$ & $623(4.3)$ & $669(4.4)$ \\
\hline Type 2 diabetes & $7,179(17.6)$ & $594(16.6)$ & $1,069(14.6)$ & $2,495(17.3)$ & $3,021(19.7)$ \\
\hline \multicolumn{6}{|l|}{ Pre-index TNFi indicated condition, $\mathrm{n}(\%)$} \\
\hline Rheumatoid arthritis & $23,101(56.8)$ & $\mathrm{I}, 5 \mathrm{I} 4(42.3)$ & $5,747(78.3)$ & $10,165(70.5)$ & $5,675(37.0)$ \\
\hline Psoriasis & $9,633(23.7)$ & $1,425(39.8)$ & $768(10.5)$ & $1,351(9.4)$ & $6,089(39.7)$ \\
\hline Psoriatic arthritis & $3,002(7.4)$ & $675(18.8)$ & $817(11.1)$ & $753(5.2)$ & $757(4.9)$ \\
\hline Ankylosing spondylitis & $1,057(2.6)$ & $260(7.3)$ & $172(2.3)$ & $158(I . I)$ & $467(3.0)$ \\
\hline \multicolumn{6}{|l|}{ Pre-index concomitant medications, n (\%) } \\
\hline Oral/self-administered corticosteroids & I8,042 (44.3) & $\mathrm{I}, 272(35.5)$ & $4,049(55.2)$ & $7,776(53.9)$ & $4,945(32.2)$ \\
\hline IV corticosteroids & $14,455(35.5)$ & $\mathrm{I}, 147(32.0)$ & $3,064(41.8)$ & $5,387(37.4)$ & $4,857(31.6)$ \\
\hline Inhaled corticosteroids & $9,693(23.8)$ & $814(22.7)$ & $1,940(26.4)$ & $3,784(26.2)$ & $3,155(20.6)$ \\
\hline SABA & $7,797(19.2)$ & $664(18.5)$ & $1,513(20.6)$ & $3,059(21.2)$ & $2,56 \mathrm{I}(16.7)$ \\
\hline LABA & $4,079(10.0)$ & $342(9.5)$ & $825(11.2)$ & $1,622(11.2)$ & $1,290(8.4)$ \\
\hline Long-acting anti-muscarinics & $\mathrm{I}, 092(2.7)$ & $90(2.5)$ & $192(2.6)$ & $455(3.2)$ & $355(2.3)$ \\
\hline Antibiotics & $28,5 \mid 3(70.1)$ & $2,46 I(68.7)$ & $5,522(75.3)$ & $10,678(74.1)$ & $9,852(64.2)$ \\
\hline Theophylline & $211(0.5)$ & $13(0.4)$ & $36(0.5)$ & $88(0.6)$ & $74(0.5)$ \\
\hline Ipratropium bromide & $2,032(5.0)$ & $142(4.0)$ & $343(4.7)$ & $846(5.9)$ & $70 I(4.6)$ \\
\hline Other biologics & $113(0.3)$ & $3(0.1)$ & $14(0.2)$ & $68(0.5)$ & $28(0.2)$ \\
\hline \multicolumn{6}{|l|}{ Physician specialty at index COPD diagnosis, n (\%) } \\
\hline Rheumatologist & $15,152(37.2)$ & $1,356(37.8)$ & $3,960(54.0)$ & $6,589(45.7)$ & $3,247(2 \mid .2)$ \\
\hline Dermatologist & $11,306(27.8)$ & $1,375(38.4)$ & $1,464(20.0)$ & $2,966(20.6)$ & $5,50 I(35.8)$ \\
\hline Pulmonologist & $3,521(8.7)$ & $294(8.2)$ & $628(8.6)$ & $\mathrm{I}, 431(9.9)$ & $\mathrm{I}, 168(7.6)$ \\
\hline
\end{tabular}

Abbreviations: DMARD, disease-modifying antirheumatic drug; IV, intravenous; LABA, long-acting beta-agonist; SABA, short-acting beta-agonist; SD, standard deviation; TNFi, tumor necrosis factor inhibitors.

LABA, ipratropium bromide, long-acting anti-muscarinics, and theophylline), and several comorbidities (anxiety, congestive heart failure, depression, hypertension, obesity, and osteoporosis) were all significantly associated with increased risk of COPD-related hospitalization or ER visit (All $P<0.05$ ) (Figure 5). Sensitivity analysis conducted among only patients with a diagnosis of RA were similar to the overall results.

Analysis of an array of clinical and demographic factors among COPD patients who underwent different treatments showed that older patients, those with worse general health and select preexisting comorbid conditions, and pretreatment with COPD medications (SABAs, LABAs, long-acting antimuscarinics, theophylline, and TNFi) had increasing hazards for COPD-related hospitalization or ER visits. Stratified analysis was conducted where four additional Cox models were fit for patients in age groups $18-44,45-54,55-64$, and $\geq 65$ years. The findings were consistent with those for the combined sample. The use of combination TNFi and nonbiologic DMARD therapy was associated with a reduction in the hazard of COPD-related hospitalization or ER visits compared to non-biologic DMARD only in all age groups, though not statistically significant for the youngest age group: 18-44 years (HR: 0.877; 95\% CI: 0.561-1.373), 45-54 years (HR: 0.731; 95\% CI: 0.563-0.949), 55-64 years (HR: 0.619 ; 95\% CI: $0.513-0.747$ ), and $\geq 65$ years (HR: 0.700 ; 95\% CI: 0.596-0.823). Similarly, there were no statistically significant differences between the TNFi only cohort and the non-biologic DMARD only cohort across all four age subgroups (Table S1). The combined model also found that the presence of pre-index period asthma, AS, and $\mathrm{PsO}$ were each associated with lower hazard of COPD-related hospitalization or ER visits during follow-up (Figure 5). 


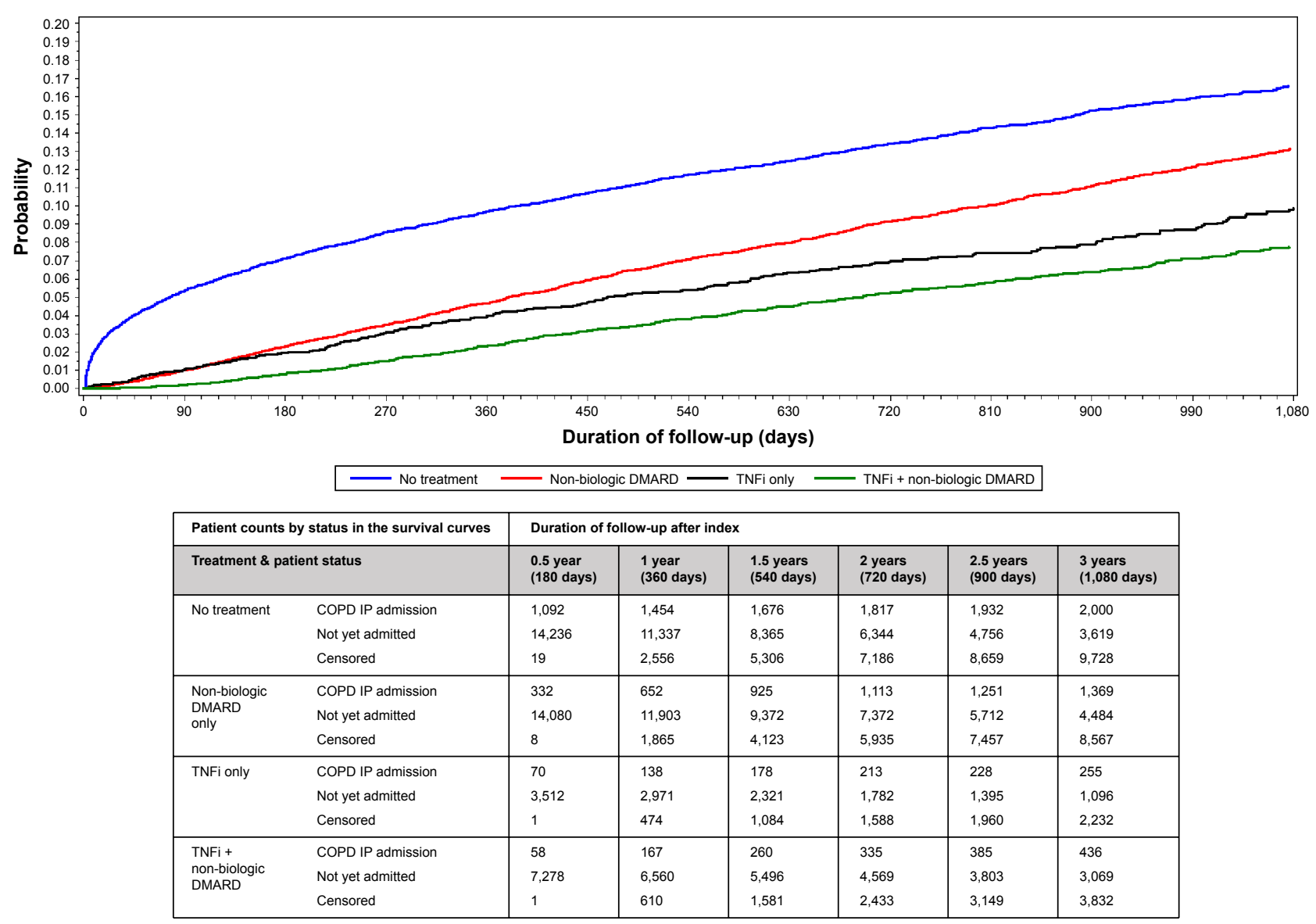

Figure 2 Unadjusted probability of first COPD-related hospitalization by days after starting treatment.

Abbreviations: TNFi, tumor necrosis factor inhibitors; IP, inpatient.

\section{Discussion}

This large retrospective database analysis of 40,687 COPD patients from a nationally representative health care administrative database found that patients on treatment containing TNFi had lower incidence rates of COPD-related hospitalization than patients treated with non-biologic DMARDs only or untreated patients. Similar findings were observed when expanding the study outcome to include both COPD-related ER visit and hospitalization. After adjusting for patient baseline demographic and clinical differences, TNFi + non-biologic DMARD treatment was associated with a significant reduction in the hazard of COPD-related hospitalization or ER visits compared to non-biologic DMARD only; however, there was no significant difference in the hazard of COPD-related hospitalization or ER visits between patients treated with TNFi only and those treated with non-biologic DMARD only. TNFi are routinely combined with non-biologic DMARDs such as methotrexate for additional efficacy though monotherapy is often employed due to adverse events such as gastrointestinal discomfort, hepatic laboratory abnormalities, and hematologic cytopenias. ${ }^{16}$

In 2008, a large claims-based analysis of RA and COPD patients treated with etanercept and infliximab reported significant reduction in the risk of COPD-related hospitalization with the use of TNFi (RR: 0.62 ; 95\% CI: $0.43-0.89$ ) compared to the untreated, exclusively driven by etanercept (RR: 0.49 ; 95\% CI: $0.29-0.82) .{ }^{13}$ However, infliximab did not have the same effect on risk reduction of hospitalization (RR: 0.95; 95\% CI: 0.59-1.52). Our current analysis was built upon this approach, with the following differences: more recent claims data (2006-2013 versus 1995-2004), larger sample size (40,687 versus 15,771$)$, younger patient sample (mean age of 60 years versus 67 years), and longer duration of follow-up (mean 28 months versus 14 months). ${ }^{13}$ Another key difference is that our analysis differentiated TNFi monotherapy from TNFi plus concomitant non-biologic DMARD therapy, whereas Suissa et $\mathrm{al}^{13}$ treated both together. Our study also examined TNFi as a class and did not evaluate the outcomes by individual agent. While differential outcomes 


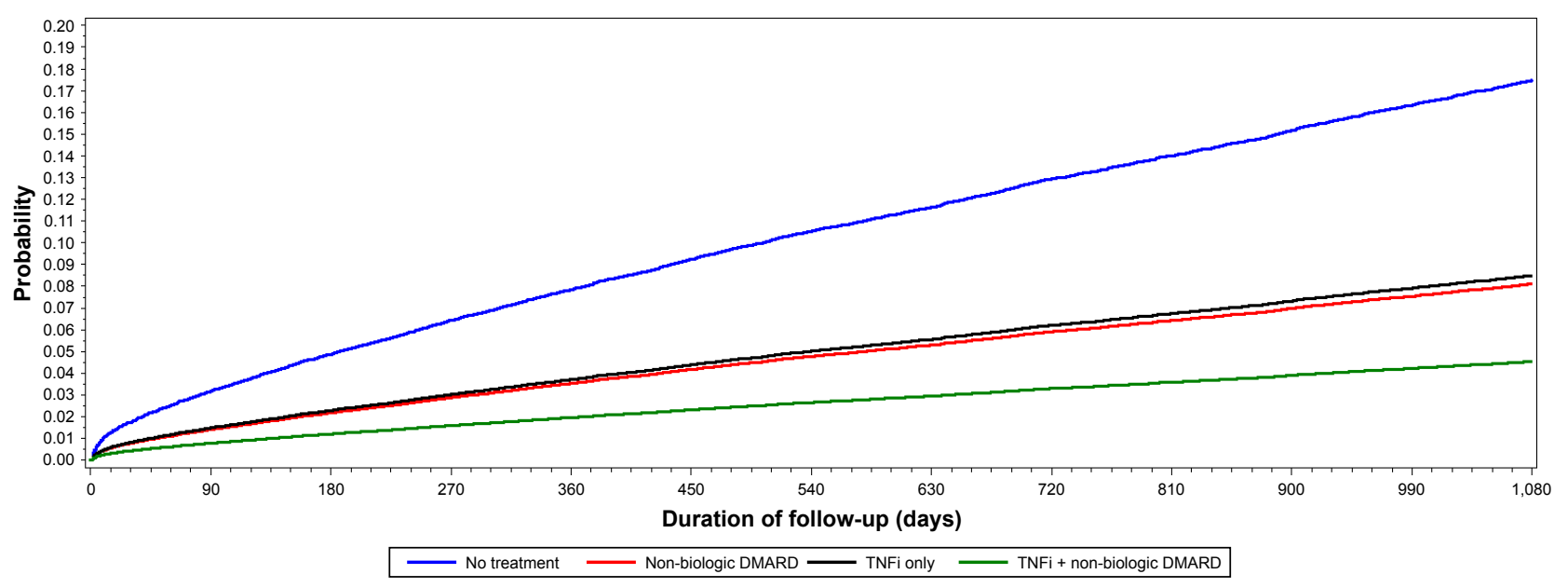

\begin{tabular}{|c|c|c|c|c|c|c|c|}
\hline \multirow{2}{*}{\multicolumn{2}{|c|}{$\begin{array}{l}\text { Patient counts by status in the survival curves } \\
\text { Treatment \& patient status }\end{array}$}} & \multicolumn{6}{|c|}{ Duration of follow-up after index } \\
\hline & & \multirow{2}{*}{$\begin{array}{l}\begin{array}{l}\mathbf{0} 5 \text { year } \\
\text { (180 days) }\end{array} \\
1,092\end{array}$} & \multirow{2}{*}{$\begin{array}{l}\begin{array}{l}1 \text { year } \\
\text { (360 days) }\end{array} \\
1,454\end{array}$} & \multirow{2}{*}{$\begin{array}{l}\mathbf{1 . 5} \text { years } \\
\text { (540 days) }\end{array}$} & \multirow{2}{*}{$\begin{array}{l}2 \text { years } \\
\text { (720 days) }\end{array}$} & \multirow{2}{*}{$\begin{array}{l}2.5 \text { years } \\
\text { (900 days) }\end{array}$} & \multirow{2}{*}{$\begin{array}{l}\begin{array}{l}3 \text { years } \\
(1,080 \text { days })\end{array} \\
2,000\end{array}$} \\
\hline No treatment & COPD IP admission & & & & & & \\
\hline & Not yet admitted & 14,236 & 11,337 & 8,365 & 6,344 & 4,756 & 3,619 \\
\hline & Censored & 19 & 2,556 & 5,306 & 7,186 & 8,659 & 9,728 \\
\hline \multirow{3}{*}{$\begin{array}{l}\text { Non-biologic } \\
\text { DMARD } \\
\text { only }\end{array}$} & COPD IP admission & 332 & 652 & 925 & 1,113 & 1,251 & 1,369 \\
\hline & Not yet admitted & 14,080 & 11,903 & 9,372 & 7,372 & 5,712 & 4,484 \\
\hline & Censored & 8 & 1,865 & 4,123 & 5,935 & 7,457 & 8,567 \\
\hline \multirow[t]{3}{*}{ TNFi only } & COPD IP admission & 70 & 138 & 178 & 213 & 228 & 255 \\
\hline & Not yet admitted & 3,512 & 2,971 & 2,321 & 1,782 & 1,395 & 1,096 \\
\hline & Censored & 1 & 474 & 1,084 & 1,588 & 1,960 & 2,232 \\
\hline \multirow{3}{*}{$\begin{array}{l}\text { TNFi + } \\
\text { non-biologic } \\
\text { DMARD }\end{array}$} & COPD IP admission & 58 & 167 & 260 & 335 & 385 & 436 \\
\hline & Not yet admitted & 7,278 & 6,560 & 5,496 & 4,569 & 3,803 & 3,069 \\
\hline & Censored & 1 & 610 & 1,581 & 2,433 & 3,149 & 3,832 \\
\hline
\end{tabular}

Figure 3 Adjusted $^{a}$ probability of first COPD-related hospitalization by days after starting treatment.

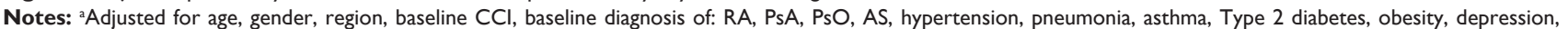
hyperlipidemia, osteoporosis, congestive heart failure, anxiety, and baseline use of: non-biologic DMARD, oral/self-administered corticosteroids, inhaled corticosteroids, physician-administered corticosteroids, LABA, SABA, long-acting anti-muscarinics, ipratropium bromide, antibiotics, and baseline biologic use (ETA, ADA, INF, GOL, CTZ, or other).

Abbreviations: AS, ankylosing spondylitis; $\mathrm{CCl}$, Deyo-Charlson Comorbidity Index; DMARD, disease-modifying antirheumatic drug; PsA, psoriatic arthritis; PsO, psoriasis; RA, rheumatoid arthritis; LABA, long-acting beta-agonist; SABA, short-acting beta-agonist; TNFi, tumor necrosis factor inhibitors; IP, inpatient; ETA, etanercept; ADA, adalimumab; INF, infliximab; GOL, golimumab; CTZ, certolizumab.

Biologic therapy (non-biologic DMARD alone is referent)

TNFi monotherapy

TNFi + non-biologic DMARD

Age, years (age $<45$ years is referent)

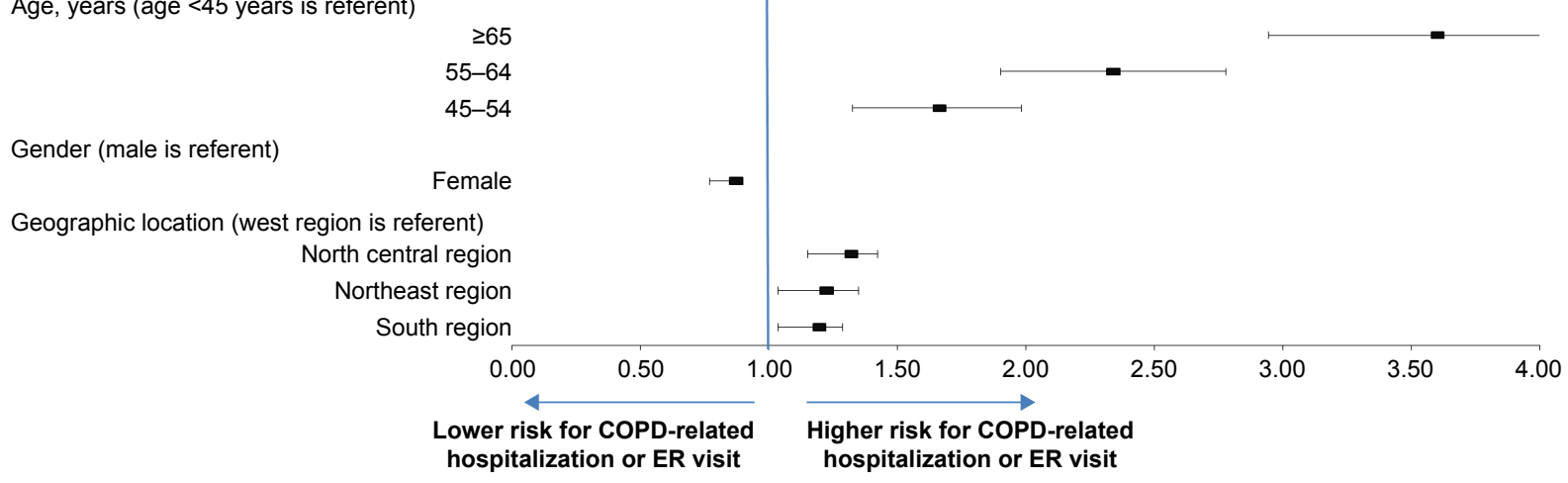

Figure 4 Hazard ratio of COPD-related hospitalization or ER visits during 3-year follow-up period.

Note: Hazard ratios with $95 \%$ confidence intervals.

Abbreviations: ER, emergency room; TNFi, tumor necrosis factor inhibitors. 
Pre-index biologic use

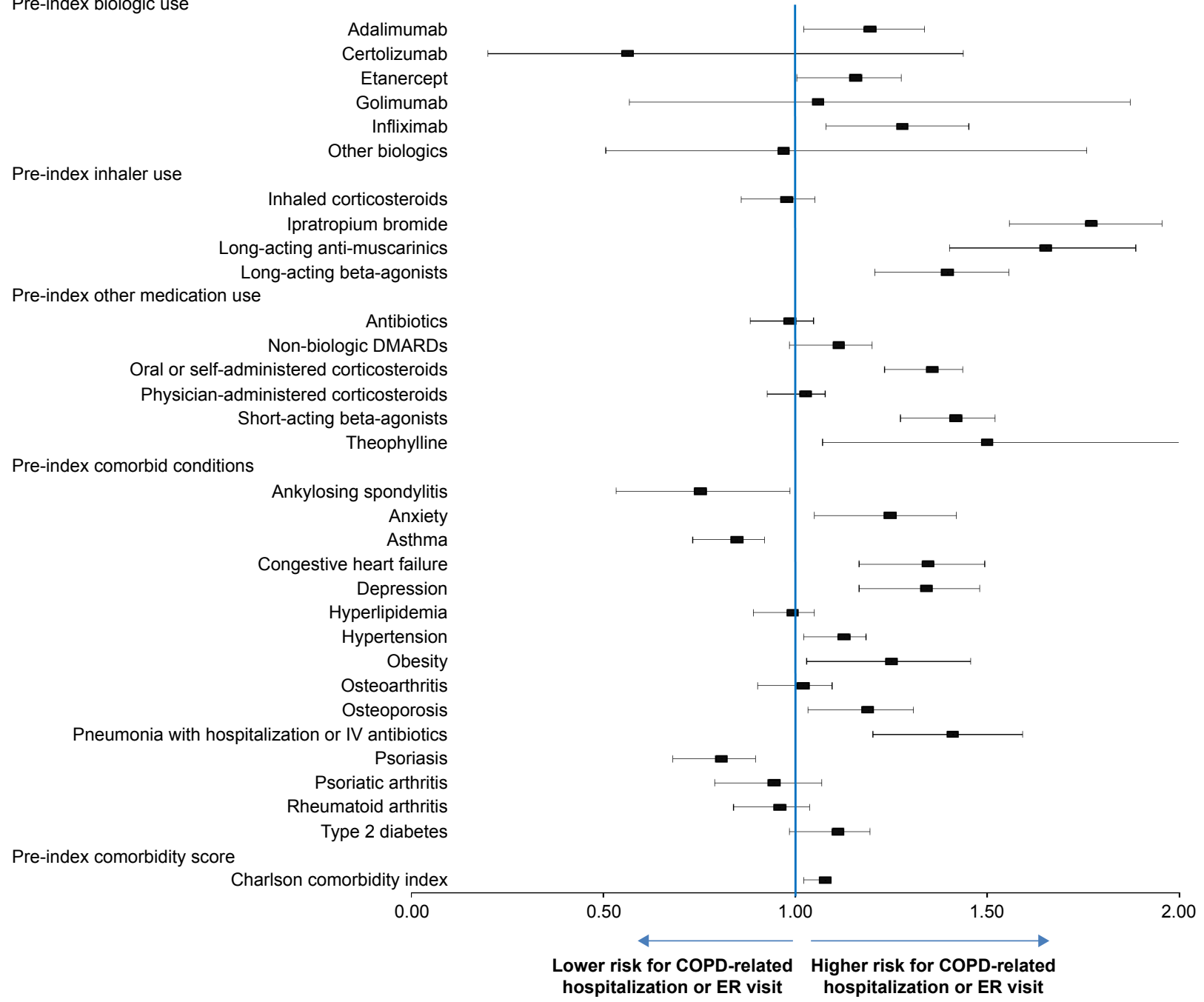

Figure 5 Hazard ratio of COPD-related hospitalization or ER visits during 3-year follow-up period, all ages combined.

Notes: Referent for medication use is no pharmacy claims during pre-index period. Referent for comorbidities is no diagnoses during pre-index period. Referent for comorbidity score is 0 during pre-index period. Hazard ratios with $95 \%$ confidence intervals.

Abbreviations: DMARD, disease-modifying antirheumatic drug; ER, emergency room; IV, intravenous.

for infliximab and etanercept have been reported in the past, there are no known published studies on newer TNFi such as certolizumab pegol and golimumab. ${ }^{13}$ Future analysis at the drug level is desirable to test the findings from this study.

\section{Limitations}

The interpretation of findings from this study should be cautioned with several limitations. Channeling bias may be present in this analysis and occurs when a high-risk subset of patients are less likely to be prescribed certain medications than other low-risk patients. Patients in all cohorts had comparable comorbidity scores and though comorbidities were controlled for in the adjusted models, the potential for channeling bias remains, especially if it is related to disease severity or other unobservable patient characteristics that could influence the study outcomes. Other limitations stem from using health insurance claims.
The identification of diagnosis relied on ICD-9 diagnosis codes which only reflect the claims which physicians submit for reimbursement. Additionally, past studies have suggested that COPD severity, timing of treatment (ie, during an acute exacerbation) and subtype of COPD may influence the efficacy of TNFi in treating COPD. ${ }^{10-12,17}$ We were unable to capture these clinical markers using medical claims and thus our findings warrant further investigation within different subsets of COPD patients incorporating this clinical data. Finally, this study only included patients covered by commercial or Medicare insurance, therefore results may not be generalizable to those with other types of coverage or the uninsured.

\section{Conclusion}

This retrospective study of COPD patients with underlying autoimmune conditions suggests that use of a TNFi alone 
confers a similar risk for COPD-related hospitalizations compared to patients receiving a non-biologic DMARD alone; however, a decreased risk was apparent among those treated with both TNFi and a non-biologic DMARD. Multiple factors were found to be related to COPD hospitalization. Further analyses are needed to better understand the impact of disease severity (both COPD and autoimmune disease) and other factors in the physicians' decision-making process as to which patients to treat with TNFi and whether there is a channeling of patients based on underlying disease profile.

\section{Acknowledgments}

The authors wish to acknowledge Santosh Tiwari for his editorial contribution to this study. Truven Health Analytics provided study design, programming, analysis, and manuscript development for major pharmaceutical and biotech firms. This manuscript, and the work described herein, was funded by Amgen Inc.

\section{Disclosure}

Drs Accortt and Chung are employees and stockholders of Amgen, Inc. Drs Bonafede and Limone are employees of Truven Health Analytics, which received a research contract to conduct this study with and on behalf of Amgen, Inc. Dr Mannino has received honoraria/consulting fees and served on speaker bureaus for GlaxoSmithKline plc, Novartis Pharmaceuticals, Pfizer Inc., Boehringer-Ingelheim, AstraZeneca PLC, Forest Laboratories Inc., Merck, Amgen, and Sunovion. Furthermore, he has received royalties from Up-to-Date, is on the Board of Directors of the COPD Foundation, and has been compensated as a medical expert in legal cases. The authors report no other conflicts of interest in this work.

\section{References}

1. Ford ES, Croft JB, Mannino DM, Wheaton AG, Zhang X, Giles WH. COPD surveillance - United States, 1999-2011. Chest. 2013;144(1):284-305.

2. Qaseem A, Wilt TJ, Weinberger SE, et al. Diagnosis and management of stable chronic obstructive pulmonary disease: a clinical practice guideline update from the American College of Physicians, American College of Chest Physicians, American Thoracic Society, and European Respiratory Society. Ann Intern Med. 2011;155(3):179-191.
3. Global Initiative for Chronic Obstructive Lung Disease (GOLD). Global Strategy for the Diagnosis, Management and Prevention of COPD, 2016. Available from http://goldcopd.org/global-strategy-diagnosismanagement-prevention-copd-2016/. Accessed October 3, 2016.

4. Thomas PS, Yates DH, Barnes PJ. Tumor necrosis factor-alpha increases airway responsiveness and sputum neutrophilia in normal human subjects. Am J Respir Crit Care Med. 1995;152(1):76-80.

5. Michel O, Dinh PH, Doyen V, Corazza F. Anti-TNF inhibits the airways neutrophilic inflammation induced by inhaled endotoxin in human. $B M C$ Pharmacol Toxicol. 2014;15:60.

6. Keatings VM, Collins PD, Scott DM, Barnes PJ. Differences in interleukin- 8 and tumor necrosis factor-alpha in induced sputum from patients with chronic obstructive pulmonary disease or asthma. Am J Respir Crit Care Med. 1996;153(2):530-534.

7. Aaron SD, Angel JB, Lunau M, et al. Granulocyte inflammatory markers and airway infection during acute exacerbation of chronic obstructive pulmonary disease. Am J Respir Crit Care Med. 2001; 163(2):349-355.

8. Vernooy JH, Küçükaycan M, Jacobs JA, et al. Local and systemic inflammation in patients with chronic obstructive pulmonary disease: soluble tumor necrosis factor receptors are increased in sputum. Am J Respir Crit Care Med. 2002;166(9):1218-1224.

9. Daldegan MB, Teixeira MM, Talvani A. Concentration of CCL11, CXCL8 and TNF-alpha in sputum and plasma of patients undergoing asthma or chronic obstructive pulmonary disease exacerbation. Braz J Med Biol Res. 2005;38(9):1359-1365.

10. Antoniu SA, Mihaltan F, Ulmeanu R. Anti-TNF-alpha therapies in chronic obstructive pulmonary diseases. Expert Opin Investig Drugs. 2008;17(8):1203-1211.

11. van der Vaart H, Koëter GH, Postma DS, Kauffman HF, ten Hacken NH. First study of infliximab treatment in patients with chronic obstructive pulmonary disease. Am J Respir Crit Care Med. 2005;172(4): 465-469.

12. Rennard SI, Fogarty C, Kelsen S, et al. The safety and efficacy of infliximab in moderate to severe chronic obstructive pulmonary disease. Am J Respir Crit Care Med. 2007;175(9):926-934.

13. Suissa S, Ernst P, Hudson M. TNF-alpha antagonists and the prevention of hospitalisation for chronic obstructive pulmonary disease. Pulm Pharmacol Ther. 2008;21(1):234-238.

14. Aaron SD, Vandemheen KL, Maltais F, et al. TNF $\alpha$ antagonists for acute exacerbations of COPD: a randomised double-blind controlled trial. Thorax. 2013;68(2):142-148.

15. Litsiou E, Semitekolou M, Galani IE, et al. CXCL13 production in B cells via Toll-like receptor/lymphotoxin receptor signaling is involved in lymphoid neogenesis in chronic obstructive pulmonary disease. $\mathrm{Am}$ J Respir Crit Care Med. 2013;187(11):1194-1202.

16. Emery P, Sebba A, Huizinga TW. Biologic and oral disease-modifying antirheumatic drug monotherapy in rheumatoid arthritis. Ann Rheum Dis. 2013;72(12):1897-1904.

17. Dentener MA, Creutzberg EC, Pennings HJ, Rijkers GT, Mercken E, Wouters EF. Effect of infliximab on local and systemic inflammation in chronic obstructive pulmonary disease: a pilot study. Respiration. 2008;76(3):275-282. 


\section{Supplementary material}

Table SI Adjusted relative risk of a COPD-related IP admission or ER visit by age

\begin{tabular}{|c|c|c|c|c|c|c|c|c|c|c|}
\hline \multirow[t]{2}{*}{ Cohort } & \multicolumn{2}{|c|}{ All ages } & \multicolumn{2}{|c|}{ I 8-44 years } & \multicolumn{2}{|c|}{ 45-54 years } & \multicolumn{2}{|c|}{ 55-64 years } & \multicolumn{2}{|c|}{$\geq 65$ years } \\
\hline & HR & $P$-value & HR & $P$-value & HR & $P$-value & HR & $P$-value & HR & $P$-value \\
\hline TNFi only & 1.003 & 0.97 & 0.530 & 0.09 & 0.999 & 0.99 & 1.175 & 0.24 & 1.002 & 0.99 \\
\hline TNFi and DMARD & 0.678 & $<0.0001$ & 0.877 & 0.57 & 0.731 & 0.02 & 0.619 & $<0.0001$ & 0.700 & $<0.000$ I \\
\hline DMARD only & 1.000 & - & 1.000 & - & 1.000 & _- & 1.000 & - & 1.000 & - \\
\hline
\end{tabular}

Note: '-' indicates referent.

Abbreviations: DMARD, disease-modifying antirheumatic drug; ER, emergency room, HR, hazard ratio; IP, inpatient; TNFi, tumor necrosis factor-alpha inhibitor.

\section{Publish your work in this journal}

The International Journal of COPD is an international, peer-reviewed journal of therapeutics and pharmacology focusing on concise rapid reporting of clinical studies and reviews in COPD. Special focus is given to the pathophysiological processes underlying the disease, intervention programs, patient focused education, and self management protocols.
This journal is indexed on PubMed Central, MedLine and CAS. The manuscript management system is completely online and includes a very quick and fair peer-review system, which is all easy to use. Visit http://www.dovepress.com/testimonials.php to read real quotes from published authors. 